\title{
Sigmoido-Uterine Fistula Caused by Ovarian Cancer
}

\author{
Brajnev Kumar Yadav', Jin-Jian Xiang1* ${ }^{*}$ Ben-Jing Cheng1, Qing-Hua Yi² \\ ${ }^{1}$ Department of General Surgery, The First Hospital Affiliated to Yangtze University, Jingzhou, China \\ ${ }^{2}$ Department of Gynecology, The First Hospital Affiliated to Yangtze University, Jingzhou, China \\ Email: ^xiangjjxiangcy@sina.com, brajnevyadav@gmail.com,309802903@qq.com,245593557@qq.com
}

How to cite this paper: Yadav, B.K., Xiang, J.-J., Cheng, B.-J. and Yi, Q.-H. (2017) Sigmoido-Uterine Fistula Caused by Ovarian Cancer. Yangtze Medicine, 1, 45-49. https://doi.org/10.4236/ym.2017.11005

Received: October 25, 2016

Accepted: March 27, 2017

Published: March 30, 2017

Copyright ( 92017 by authors and Scientific Research Publishing Inc. This work is licensed under the Creative Commons Attribution International License (CC BY 4.0).

http://creativecommons.org/licenses/by/4.0/ (c) (i) Open Access

\begin{abstract}
A 67-year-old woman presented with abdominal distension and difficulty in defecation. She had a huge mass in the left lower abdomen and hyperamylasemia with normal pancreatic-type amylase (P-AMY). Nuclear magnetic resonance and computed tomography scan revealed a huge pelvic mass, but the origin of mass wasn't certain. After discussion with the multidisciplinary team, ultrasonography guided pathological biopsy of the mass was done. $\mathrm{Pa}$ thological biopsy showed that the mass was poorly differentiated adenocarcinoma, which may be originated from ovary. Patient was on neo-adjuvant chemotherapy. After one and a half months of chemotherapy, the patient developed colorectal-reproductive system fistula with hyperpyrexia. Laparatomy with resection of mass, sigmoid colon, left ovary and part of uterus, proximal colostomy with closure of the distal rectum and end to end anastomosis of left ureter with DJ tube drainage (left ureter invaded by tumor confirmed intra operation) was done. Operative finding: Fistula between sigmoid colon and uterus through the tumor.
\end{abstract}

\section{Keywords}

Sigmoido-Uterine Fistula, Ovarian Cancer, Hyperamylasemia

\section{Introduction}

When ovarian masses are too big, especially invading the surrounding tissue, they can induce visceral fistula and sometimes difficult to clarify the origins. Some ovarian cancer may be accompanied by hyperamylasemia (elevated salivary-type amylase, S-AMY) [1]. We present a case report of patient with sigmoido-uterine fistula caused by ovarian cancer and hyperamylasemia.

\section{Case Report}

A 67-year-old woman presented in the department of medicine at local hospital 
with loss of appetite for 1 year and weight loss about $20 \mathrm{~kg}$ in 2 months. She had abdominal distension and difficulty in defecation, but no abdominal pain, vomiting and diarrhea. She had a history of cholelithiasis, hypertension and pulmonary tuberculosis. Physical examination revealed a huge mass in the left lower abdomen. The patient had hyperamylasemia and normal pancreatic-type amylase (serum amylase $908 \mathrm{U} / \mathrm{L}$, serum pancreatic-type amylase $84 \mathrm{U} / \mathrm{L}$, urine amylase $978 \mathrm{U} / \mathrm{L}$, urine pancreatic-type amylase $150 \mathrm{U} / \mathrm{L}$ ). Routine blood test showed increased white blood cell count $(16.07 \times 109 / \mathrm{L})$ and decreased hemoglobin $(82$ g/L). Serum CRP was increased $(139.45 \mathrm{mg} / \mathrm{L})$. Serum CA125 $(603.9 \mathrm{U} / \mathrm{ml})$ and CA15-3 (100.6 U/ml) were increased and AFP $(2.53 \mathrm{ng} / \mathrm{ml})$, CEA $(1.07 \mathrm{ng} / \mathrm{ml})$ and CA19-9 (3.69 U/ml) were normal. A computed tomography scan (CT-scan) of the pancreas revealed cholelithiasis, the left hydroureteronephrosis, the left adrenal nodule, but no abnormalities was found in pancreas. Nuclear magnetic resonance scan (MRI-scan) of pelvis showed a huge pelvic mass, which may be originated from uterus and free fluid in the pelvic cavity.

The patient was admitted to gynecology department of our hospital for one week. Multiple re-examination of amylase (AMY) was still elevated and pancreatic-type amylases (P-AMY) were still normal. Colonoscopy was performed and revealed a huge tumor in sigmoid [Figure 1(a)] and biopsy showed necrotic tissue. Gynecological ultrasound revealed multiple uterine fibroids. Computed tomography angiography plus urography plus 3D reconstruction $(\mathrm{CTA}+\mathrm{CTU}+$ 3D) considered a huge malignant tumor $[11.4 \mathrm{~cm} \times 11.6 \mathrm{~cm} \times 11.2 \mathrm{~cm}$, Figure 1 (b)] in sigmoid colon, some gas in tumor, tumor blood supplied from inferior mesenteric artery [Figure 1(c)], the left lower ureter was invaded by the tumor and upper left ureter and renal pelvis were dilatated [Figure 1(d)]. In order to further clarify the diagnosis and treatment, a discussion with the multidisciplinary teams (MDTs, involving department of gynecology, general surgery, urinary surgery, oncology, gastroenterology and radiology) was performed. The discussion results: 1) Hyperamylasemia likely caused by the tumor. 2) Ultrasonograpy guided pathological biopsy of the mass to clear the origin of tumor, which may be originated from sigmoid or ovary or retroperitoneal tissue. 3) Tumor can't be radically resected at present herein, it's better to do pre-operative

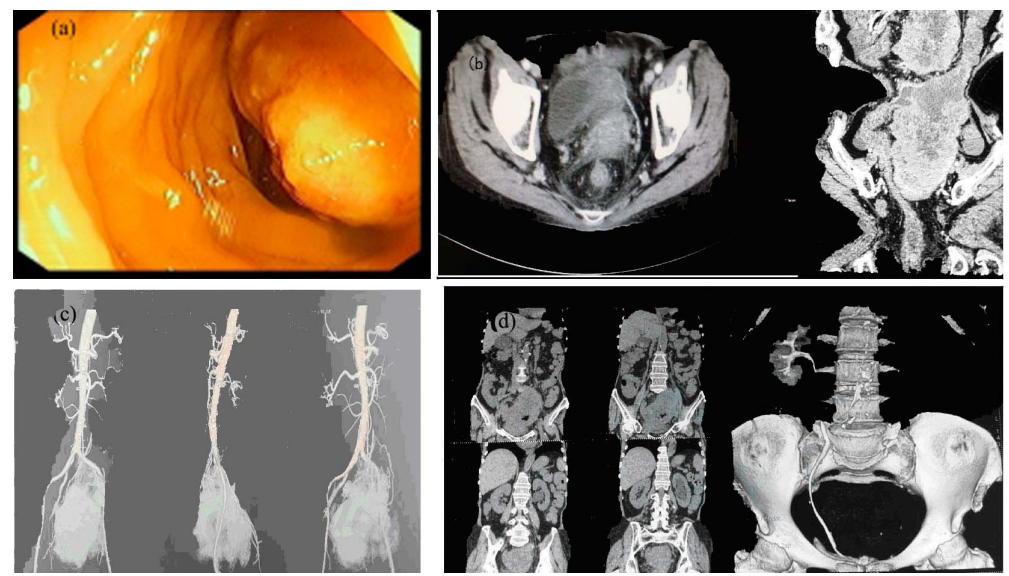

Figure 1. Colonoscopy and imaging examination. 
neo-adjuvant chemoradiotherapy or molecular targeted therapy according to tumor histological tissue types and origins. Pathological biopsy showed poorly differentiated adenocarcinoma, which originated from ovary, [immunohistochemistry: CK7(+), CK20(-), Villin(-), CDX2(-), CA19-9(-), CA125(+), CEA(-), Ki67(+): 70\% - 80\%]. The patient underwent 2 cycles of chemotherapy (3 weeks apart) for ovarian cancer with (paclitaxel $135.48 \mathrm{mg} / \mathrm{m}^{2}$, total dose $210 \mathrm{mg}$, carboplatin $258.06 \mathrm{mg} / \mathrm{m}^{2}$, total dose $400 \mathrm{mg}$ for 3 days per cycle). After the first cycle of chemotherapy, Serum-AMY, CA125 and CA15-3 decreased and tumor obviously shrank $(5.6 \mathrm{~cm} \times 5.1 \mathrm{~cm} \times 4.9 \mathrm{~cm})$. Ten days after the second cycle chemotherapy, the stool was coming out from patient's vagina with hyperpyrexia , which showed the patient had colorectal-reproductive system fistula. Combining with department of gynecology, general surgery and urinary surgery, laparatomy with resection of mass, sigmoid colon, left ovary and part of uterus, proximal colostomy with closure of the distal rectum and end to end anastomosis of left ureter with DJ tube drainage (left ureter invaded by tumor confirmed intra operation) was done. Operative findings: sigmoido-uterine fistula through the tumor, one end in the sigmoid colon and other end in left cornua uteri. Histological examination showed necrotic tissue. The patient recovered well and underwent post surgery adjuvant chemotherapy. One month after surgery serum-AMY, CA125 and CA15-3 dropped back to normal and CT abdomen showed no residual tumor.

\section{Discussion}

Human $\alpha$-amylase includes salivary-type isoamylase and pancreatic-type isoamylase. Salivary-type amylase or gene is present in normal human salivary glands, thyroid, lungs and the female genital tract [2] [3]. In clinical cases, elevated salivary-type amylases are observed in many tumors such as lung cancer [4], pancreatic cancer [5], stomach cancer [6], uterine tumors [7], ovarian cancer [8] [9] [10], osteosarcoma [11], multiple myeloma [12]. In our case, the tumor originated from the ovary. The patient had hyperamylasemia and normal pancreatic-type amylase, so we can infer the patient had elevated salivary-type amylase. When the patient was hospitalized in department of medicine at local hospital with hyperamylasemia, she was once falsely diagnosed with pancreatitis. So when the patients have hyperamylasemia, especially with normal pancreatic-type amylase, we must consider possibility of amylase-producing tumors and further examine such as imaging examination and tumor markers etc should be performed.

The origin of the tumor was not certain before operation in our case. The tumor was huge and located in the pelvic cavity, may be originated from sigmoid or ovary or uterus or urinary bladder or retroperitoneal tissue. So we organized a discussion with the multidisciplinary team. We considered the discussion with the multidisciplinary teams was important to diagnose and treat complex neoplasms according to our some cases and some references [13] [14]. After the discussion with the multidisciplinary teams, the possibility of origins from uterus or urinary bladder was excluded, but the possibility of origin from sigmoid or 
ovary or retroperitoneal tissue was still not certain. Combining the result of colonoscopy and biopsy (necrotic tissue), gas (maybe come from intestinal tract or caused by tumor necrosis) in tumor and tumor blood supplied from inferior mesenteric artery, sigmoid colon tumor couldn't be excluded. Given hyperamylasemia with normal pancreatic-type amylase and rising serum CA125 and CA15-3, ovarian cancer also couldn't be excluded. In view of location, some rare tumors originated from retroperitoneal tissue needs to be considered. To clarify the diagnosis and treatment, ultrasonography guided pathological biopsy of the mass was performed after discussion with the multidisciplinary teams. In consideration of highly unlikely radical resection of tumor, if sigmoid stromal tumor was confirmed by pathological biopsy, the patient needed molecular targeted therapy (usually with imatinib) before surgery; if tumor originated from ovarian tissues, pre-operation neo-adjuvant chemotherapy might shrink the tumor so that we could radically resect the tumor; if tumor was sigmoid carcinoma, prognosis of patient was poor. Pathological biopsy showed the tumor was poorly differentiated adenocarcinoma, which might be originated from ovary. [immunohistochemistry: CK7(+), CK20(-), Villin(-), CDX2(-), CA19-9(-), CA125(+), CEA(-), Ki67(+): 70\% - 80\%].

Ten days after the second cycle chemotherapy, the stool was coming out from patient's vagina with hyperpyrexia, which showed the patient had colorectal-reproductive system fistula. During surgery, we found sigmoido-uterine fistula through the tumor (ovarian mass, one end in the sigmoid colon and other end in left cornua uteri). So gas in tumor revealed by CT-scan before surgery may be from the fistula between sigmoid colon or uterus and tumor, not just only caused by tumor necrosis. CTA $+\mathrm{CTU}+3 \mathrm{D}$ revealed tumor blood was supplied from inferior mesenteric artery, which made us suspect the tumor perhaps was originated from sigmoid colon. However the tumor was originated from ovary actually, so tumor blood vessel from inferior mesenteric artery was angiogenesis.

After the first cycle chemotherapy, Serum-AMY, CA125 and CA15-3 decreased and tumor obviously shrank. Histological examination showed necrotic tissue. Serum-AMY, CA125 and CA15-3 dropped back to normal and CT showed no residual tumor 1 month after operation. So, we considered the patient was in pathologic complete remission (PCR) after chemotherapy. The patient need follow up still under control in the future.

\section{Acknowledgements}

We appreciate the guidance given by the professor Fu Tian from department of gastrointestinal surgery.

\section{Conflicts of Interest}

The authors have no conflicts of interests relevant to this article.

\section{References}

[1] Moriyama, T. (2008) Sialyl Salivary-Type Amylase Associated with Ovarian Cancer. 
Clinica Chimica Acta, 391, 106-111.

[2] Hayashi, Y., Fukayama, M., Koike, M. and Nakayama, T. (1986) Amylase in Human Lungs and the Female Genital Tract. Histochemical and Immunohistochemical Localization. Histochemistry, 85, 491-496. https://doi.org/10.1007/bf00508431

[3] Seyama, K., Nukiwa, T., Takahashi, K., Takahashi, H. and Kira, S. (1994) Amylase MRNA Transcripts in Normal Tissues and Neoplasms: The Implication of Different Expressions of Amylase Isogenes. Journal of Cancer Research and Clinical Oncology, 120, 213-220. http://dx.doi.org/10.1007/BF01372559

[4] Yamazaki, S., Ebisawa, S., Yasuo, M., Urushihata, K., Koizumi, T., Fujimoto, K. and Kubo, K. (2007) Small-Cell Lung Carcinoma Produces Salivary-Type Amylase: A Case Report with Review. Internal Medicine, 46, 883-887.

http://dx.doi.org/10.2169/internalmedicine.46.6205

[5] Shimamura, J., Fridhandler, L. and Berk, J.F. (1976) Nonpancreatic-Type Hyperamylasemia Associated with Pancreatic Cancer. American Journal of Digestive Diseases, 21, 340-345. http://dx.doi.org/10.1007/BF01071849

[6] Nomura, H., Tokumitsu, S.I. and Takeuchi, T. (1980) Ultrastructural, Cytochemical, and Biochemical Characterization of Alpha-Amylase Produced by Human Gastric Cancer Cells in Vitro. Journal of the National Cancer Institute, 64, 1015-1024.

[7] Ueda, G., Yamasaki, M., Inoue, M., Tanaka, Y., Inoue, Y., Nishino, T. and Ogawa, M. (1986) Immunohistochemical Demonstration of Amylase in Endometrial Carcinoma. International Society of Gynecological Pathologists, 5, 47-51. http://dx.doi.org/10.1097/00004347-198603000-00005

[8] Corlette, M.B., Dratch, M. and Sorger, K. (1978) Amylase Elevation Attributable to an Ovarian Neoplasm. Gastroenterology, 74, 907-909.

[9] Hayakawa, T., Kameya, A., Mizuno, R., Noda, A., Kondo, T. and Hirabayashi, N. (1984) Hyperamylasemia with Papillary Serous Cystadenocarcinoma of the Ovary. Cancer, 54, 1662-1665.

http://dx.doi.org/10.1002/1097-0142(19841015)54:8\%3C1662::AID-CNCR28205408 29\%3E3.0.CO;2-U

[10] Tohya, T., Shimajiri, S., Onoda, C. and Yoshimura, T. (2004) Complete Remission of Ovarian Endometrioid Adenocarcinoma Associated with Hyperamylasemia and Liver Metastasis Treated by Paclitaxel and Carboplatin Chemotherapy: A Case Report. International Journal of Gynecological Cancer, 14, 378-380. http://dx.doi.org/10.1111/j.1048-891x.2004.014225.x

[11] Mäsiar, P.J. (1984) Serum Amylase and Isoamylases in Malignant Bone Tumours. Neoplasma, 31, 351-359.

[12] Ok, S.J., Kim, I.S., Lee, E.Y., Kang, J.E., Lee, S.M. and Song, M.K. (2014) A Case of Salivary-Type Amylase-Producing Multiple Myeloma Presenting as Mediastinal Plasmacytoma and Myelomatous Pleural Effusion. Annals of Laboratory Medicine, 34, 463-465. http://dx.doi.org/10.3343/alm.2014.34.6.463

[13] Brännström, F., Bjerregaard, J.K., Winbladh, A., Nilbert, M., Revhaug, A., Wagenius, G. and Mörner, M. (2014) Multidisciplinary Team Conferences Promote Treatment According to Guidelines in Rectal Cancer. Acta Oncologica, 7, 1-7. http://dx.doi.org/10.3109/0284186X.2014.952387

[14] Prades, J., Remue, E., van Hoof, E. and Borras, J.M. (2015) Is It Worth Reorganising Cancer Services on the Basis of Multidisciplinary Teams (MDTs)? A Systematic Review of the Objectives and Organisation of MDTs and Their Impact on Patient Outcomes. Health Policy, 119, 464-474.

. http://dx.doi.org/10.1016/j.healthpol.2014.09.006 
Submit or recommend next manuscript to SCIRP and we will provide best service for you:

Accepting pre-submission inquiries through Email, Facebook, LinkedIn, Twitter, etc. A wide selection of journals (inclusive of 9 subjects, more than 200 journals)

Providing 24-hour high-quality service

User-friendly online submission system

Fair and swift peer-review system

Efficient typesetting and proofreading procedure

Display of the result of downloads and visits, as well as the number of cited articles Maximum dissemination of your research work

Submit your manuscript at: http://papersubmission.scirp.org/

Or contact ym@scirp.org 